\title{
Research on vertical launching missile jet flow with jet vane
}

\section{Yongyue $\mathrm{LI}^{1, \mathrm{a}}$, Aolin $\mathrm{ZHANG}{ }^{1, a}$ and Chengde WANG ${ }^{1, a}$}

${ }^{1}$ Department of Aerospace Engineering, Beijing Institute of Technology,Beijing 100081, China.

abitysz@bit.edu.cn

Keywords: Jet vane, jet flow, computational fluid dynamic, deflector.

\begin{abstract}
In order to research the impact on the surrounding environment of the high temperature and high pressure jet flow produced in the process of missile vertical launching with jet vane, the structured grids was built, and the computational fluid dynamic model was used to simulate the launching vehicle jet flow. The temperature and pressure contour of the deflector and baffle was obtained. The results shows that the ablation on the deflector was obvious, and the high temperature area was distributed by X shape. By comparing the actual experiment, we found the calculation of the simulation was reasonable, and it provided a reference for the follow study.
\end{abstract}

\section{Introduction}

The missile vertical launching has the characteristics of simple and quick[1], it is widely used in many kinds of missile launch. The high temperature and high pressure jet flow produced in the process of missile vertical launching will cause severe ablation and impact[2], now we use the deflector to lead the jet flow. Jet vane is a kind of missile control plane[3], at the beginning of the missile launching, it was used to control the initial wheel for the missile. With the impact of the jet vane, the jet flow produced by the nozzle will be impeded. The document[4] has studied the effect for the plane of the jet flow produced by solid rocket motor. The document[5]shows the impact of jet flow during the process of the concentric canister launching. The document[6]has studied the temperature distribution of the jet flow during the process of the concentric canister launching by numerical simulation. Now the study of the jet flow with jet vane is little.

\section{Physical Model}

Three-dimensional N-S equation is used for the numerical simulation; the Control Equations[7]are shown as follow:

Continuum equations is shown as follow

$$
\frac{\partial \rho}{\partial t}+\nabla \cdot\left(\rho u_{i}\right)=0
$$

Momentum equations is shown as follow

$$
\frac{\partial\left(\rho u_{\mathrm{i}}\right)}{\partial t}+\nabla \cdot\left(\rho u_{\mathrm{i}} \vec{v}\right)=-\frac{\partial p}{\partial x_{\mathrm{i}}}+\overrightarrow{F_{p}}
$$

Energy equations is shown as follow

$$
\frac{\partial(\rho T)}{\partial t}+\operatorname{div}(\rho T \boldsymbol{u})=\operatorname{div}\left(\frac{k}{c_{p}} \operatorname{grad} T\right)+S_{T}
$$

Where, $\rho$ is flow density, $u_{i}$ is flow velocity in i direction, $\vec{v}$ is velocity vector, $p$ is the flow pressure, $\overrightarrow{F_{p}}$ is momentum source term, $C_{p}$ is stated specific heat, $T$ is static temperature, $k$ is heat transfer coefficient, $S_{T}$ is internal heat source.

Turbulence Equations is shown as follow 


$$
\begin{gathered}
\frac{\partial(\rho k)}{\partial t}+\frac{\partial\left(\rho k u_{i}\right)}{\partial x_{i}}=\frac{\partial}{\partial x_{j}}\left[\alpha_{k} \mu_{e f f} \frac{\partial k}{\partial x_{j}}\right]+G_{k}+\rho \varepsilon \\
\frac{\partial(\rho \varepsilon)}{\partial t}+\frac{\partial\left(\rho \varepsilon u_{i}\right)}{\partial x_{i}}=\frac{\partial}{\partial x_{j}}\left[\alpha_{\varepsilon} \mu_{e f f} \frac{\partial \varepsilon}{\partial x_{j}}\right]+\frac{C_{1 \varepsilon}^{*} \varepsilon}{k} G_{k}-C_{2 \varepsilon} \rho \frac{\varepsilon^{2}}{k}
\end{gathered}
$$

Where,

$$
\begin{gathered}
\mu_{e f f}=\mu+\mu_{i} \\
\mu_{i}=\rho C_{\mu} \frac{k^{2}}{\varepsilon} \\
C_{\mu}=0.0845, \quad \alpha_{k}=\alpha_{\varepsilon}=1.39 \\
C_{1 \varepsilon}^{*}=C_{1 \varepsilon}-\frac{\eta\left(1-\eta / \eta_{0}\right)}{1+\beta \eta^{3}} \\
C_{1 \varepsilon}=1.42, \quad C_{2 \varepsilon}=1.68 \\
\eta=\left(2 E_{i j} \bullet E_{i j}\right)^{1 / 2} \frac{k}{\varepsilon} \\
E_{i j}=\frac{1}{2}\left(\frac{\partial u_{i}}{\partial x_{j}}+\frac{\partial u_{j}}{\partial x_{i}}\right) \\
\eta_{0}=4.377, \quad \beta=0.012
\end{gathered}
$$

\section{Calculation Model}

Fig.1.is the drawing of the computational model, the launch box is octagonal, and the deflector is single-faced deflector, the baffle is at the end of the deflector, under the deflector is the ground. Fig.2.is the drawing of the nozzle and jet vane, the access of the nozzle is pressure inlet boundary condition, total pressure is $9 \mathrm{MPa}$, and total temperature is $3100 \mathrm{~K}$. Free boundary is the pressure outlet boundary condition, the pressure is $101325 \mathrm{~Pa}$, the temperature is $300 \mathrm{~K}$, The compute mode is second order upwind.

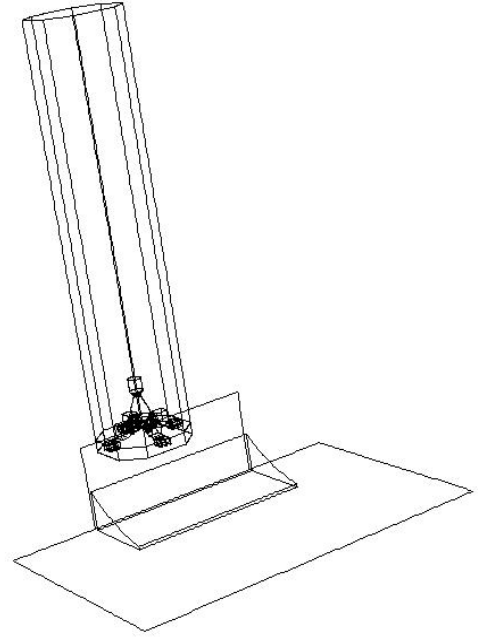

Fig.1. computational model

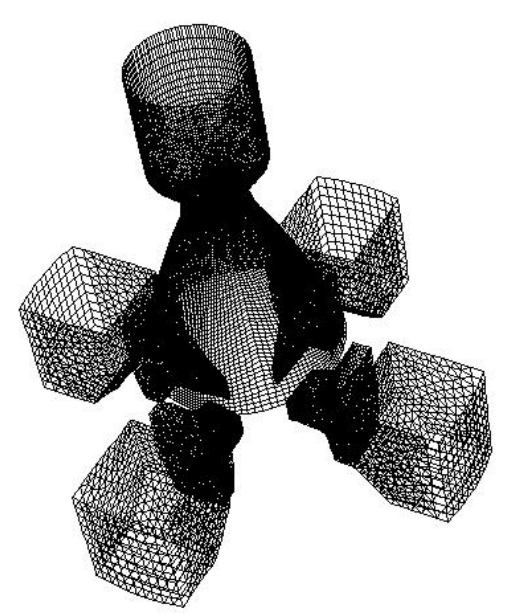

Fig.2. model of nozzle and jet vane 


\section{Results and Discussions}

The discussions of the deflector. The temperature and pressure contours on the deflector is shown in Fig.3.and Fig.4.
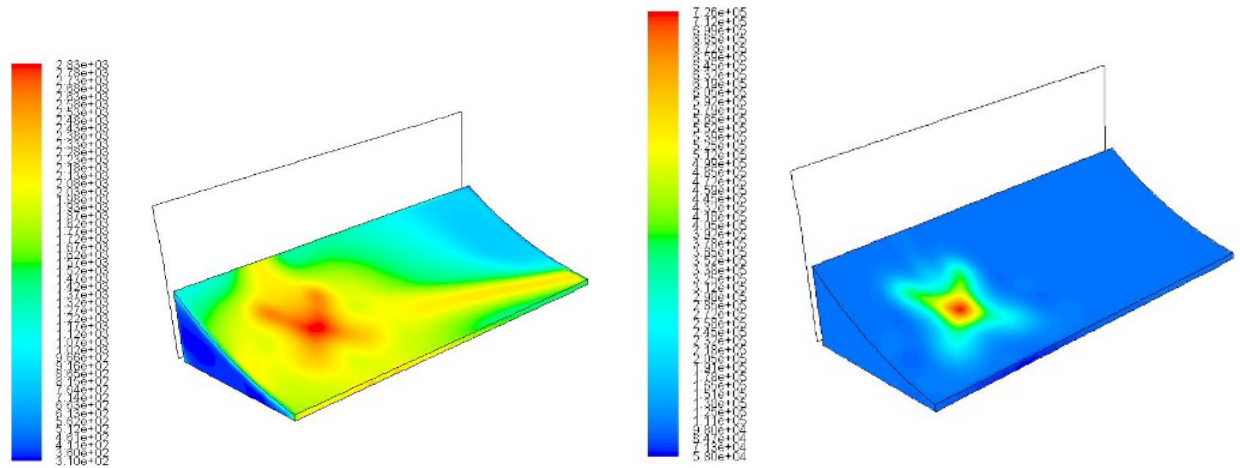

Fig.3. temperature contours on the deflector Fig.4. pressure contours on the deflector

The Fig.3.shows that the high temperature area on the deflector is showed as X shape, the highest temperature is at the center of $\mathrm{X}$ shape, it is $3097 \mathrm{~K}$, and the temperature is gradually reduced from the center to the edge. The Fig.3.shows that the highest pressure is also at the center of $\mathrm{X}$ shape, it is about 7.2 MPa, and it is reduced from the center to the edge.

The discussions of the baffle.The temperature and pressure contours on the baffle is shown in Fig.5.and Fig.6.
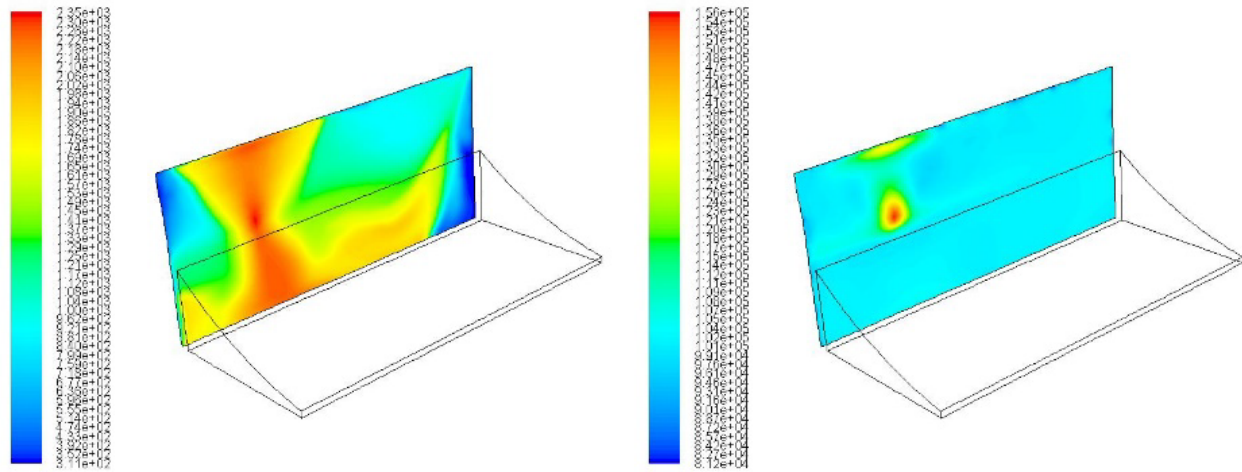

Fig.5. temperature contours on the baffle Fig.6. pressure contours on the baffle

The Fig.5.shows that the high temperature area on the baffle is next to the top of the deflector, it is $2350 \mathrm{~K}$. When the jet flow touch the plane of the deflector, it will spread along the face of the deflector, then some of the jet flow run up against the baffle, it lead to gas accumulation here. The Fig.6.shows that the highest pressure is next to the top edge of the deflector, it is $1.6 \mathrm{MPa}$. Compared to the temperature and pressure on the deflector, it is much smaller.

The discussions of the global model.The pathline of the jet flow is shown in Fig.5. The temperature contours on the global model is shown in Fig.6.

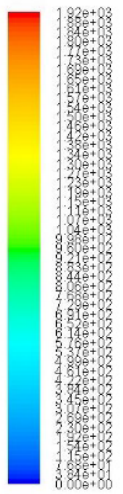

Fig.7. pathline of the jet flow
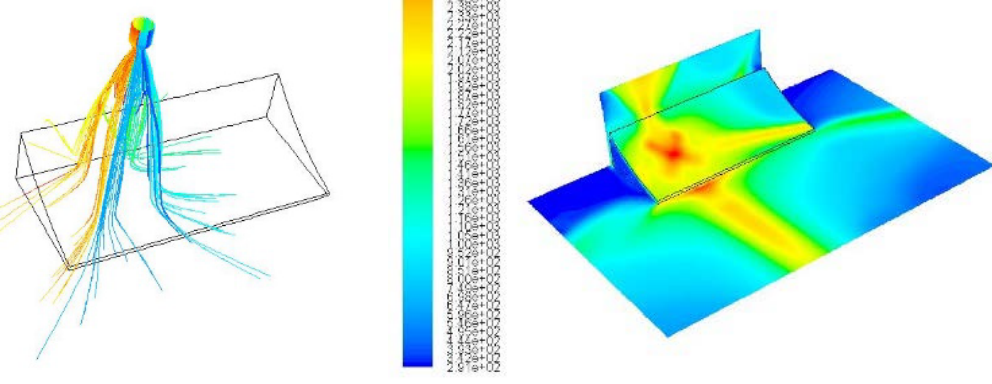

Fig.8. temperature contours on the global model 
The Fig.7.shows that when the jet flow meet the plane of the deflector, it change into four line. The Fig.8.shows the temperature contours on the global model, we can see that the highest temperature area is shown as $\mathrm{X}$ shape, and most of the jet flow to the front of the deflector, the jet flow which stayed at the two sides is little, it accounted that the deflector is good.

The drawing after the experiment.The picture of the X shape on the deflector is shown in Fig.9.

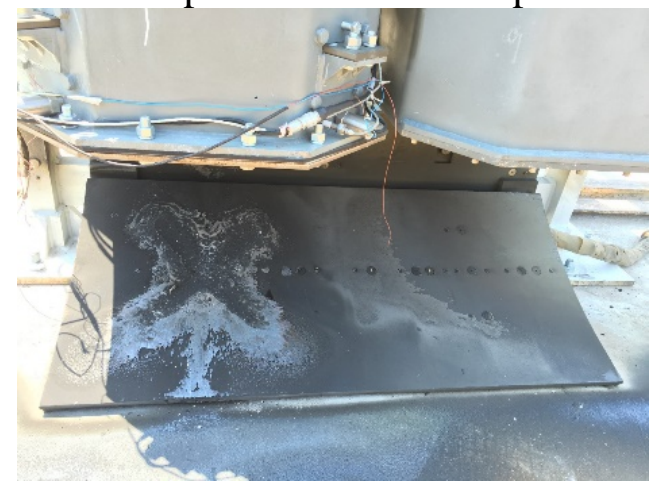

Fig.9. the picture of the $\mathrm{X}$ shape on the deflector

The Fig.9.shows that, the plane of the deflector has been badly damaged by the jet flow, under the influence of the jet vane, the damaged area is shown as $\mathrm{X}$ shape.

\section{Conclusions}

This article has built the structured grids and the computational fluid dynamic model, using simulation and real experiment to study the process of missile vertical launching with jet vane, we get the following conclusions: Under the influence of the jet vane, the high temperature area on the deflector is showed as X shape, and the plane of the deflector has been badly damaged; except the X area on the deflector, the ablation in other place is not serious, and most of the jet flow to the front of the deflector, the jet which stayed at the two sides is little, it accounts that the deflector is good; The results of the simulation is close to the real experiment, it accounts that the results of the simulation can be believed.

\section{References}

[1] Kules J J. "MK 41 vertical launching system fleet application” Naval Engineering Journal, pp, 174-184 1985,97 (4).

Reference to a book:

[2] ZHAO Cheng-qing, JIANG Yi. "The Dynamics of the Jet Flow” The publishing company of the Beijing institute of the technology, in press.

[3] HOU Qing-hai. “Air-to-air missile pneumatic jet vane design technology” Aero Weaponry, pp, 34-40 2000, 41（6）.

[4] MA Yan-li, JIANG YI, HAO Ji-guang. "Study on impact effect of solid rocket motor exhaust plume to the launching platform” Journal of Solid Rocket Technology, pp， 373-376， 33 (4),2010. [5] MA Yan-li, JIANG YI, WANG Wei-chen. "Study on impact effect of combustion gas jet during concentric canister launching process” Journal of Solid Rocket Technology, pp , 61-63, 34 (1) 2011.

[6] LIN Cui-lang, BI Shi-hua "Numerical Simulation of the Combustion-gas Temperature Field in Concentric Canister Launcher” Journal of Projectiles, Rockets, Missiles and Guidance, pp, 160-162, 27 (5), 2007.

[7] MIAO Rui-sheng. "Gas dynamics for Launch" The publishing company of the Beijing institute of the technology, in press. 